\title{
An invertebrate with a backbone
}

by Gregory D. Larsen

SCIENTIFIC NAME

Sepia officinalis

TAXONOMY

PHYLUM: Mollusca

CLASS: Cephalopoda

ORDER: Sepiida

FAMILY: Sepiidae

\section{Physical description}

The common cuttlefish is a cephalopod mollusk that predominantly inhabits shallow waters of the Mediterranean, North and Baltic seas. Common cuttlefish are found near sandy or muddy substrates, where they predate on small fish and invertebrates. They can grow up to $49 \mathrm{~cm}$ in mantle length and $4 \mathrm{~kg}$ in weight in temperate waters.

Cuttlefish are equipped with eight suckered arms and two longer, fully retractable tentacles, which they use to snatch prey. Cuttlefish lack an external shell and contain their viscera in an exposed mantle located behind the head and arms. A fringe extends from this mantle to form lateral fins.

Like many cephalopods, cuttlefish are colorblind but can discern linearly polarized light, owing to their orthogonally arranged retinal photoreceptors. This ability allows cuttlefish to detect both substrate patterns and other organisms in challenging conditions, such as low light intensity and high water turbidity ${ }^{1,2}$. Such enhanced acuity supports the cuttlefish's activities as a visual predator and camouflage specialist.

\section{Research résumé}

Ironically, their impressive camouflage abilities attract substantial research attention to cuttlefish. Cuttlefish make extensive use of visual information to manipulate their skin coloration, texture and arm postures to blend in with complex backgrounds $s^{3,4}$.

Cuttlefish complement these behaviors with unique physiological features that visually disrupt their discernible body shape, including light-scattering chromatophores and complex papillary muscles ${ }^{5,6}$. These adaptations have inspired biomimetic designs for camouflage technology that attempt to synthetically reproduce the dynamic coloration and texture of cuttlefish skin ${ }^{7,8}$.

The field of biomedical materials has also taken a strong interest in the cuttlefish, particularly in a feature that sets it apart from its phyletic peers: its backbone. The cuttlebone, a chambered internal shell composed of calcium carbonate, provides structure to cuttlefish and allows them to control their buoyancy. Researchers have manufactured

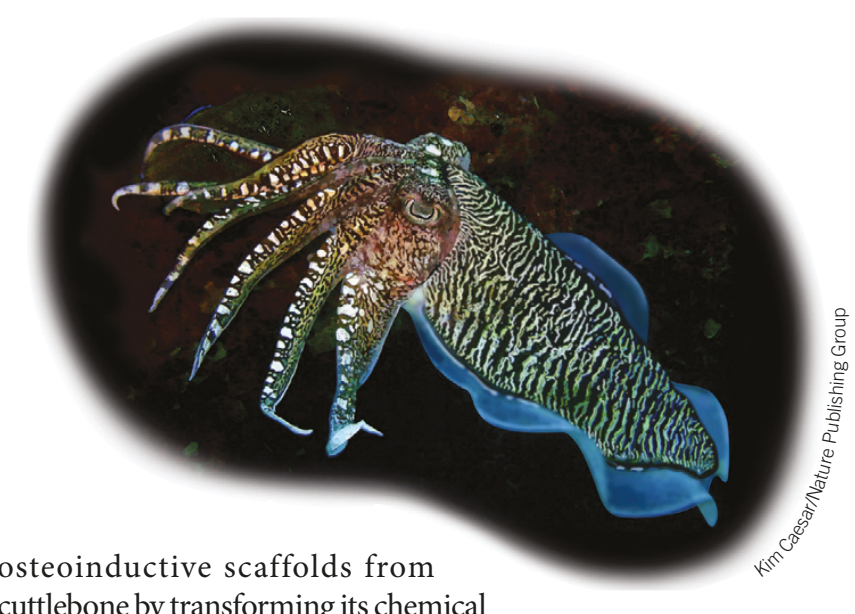

cuttlebone by transforming its chemical

composition to hydroxyapatite while maintain-

ing its natural porous structure to encourage tissue growth and vascularization $^{9,10}$. In vivo experiments with rabbits have shown successful tissue growth and bone replacement in cuttlebone-derived scaffolds ${ }^{11}$. With high abundance and low cost, cuttlebone might become an important component in bone reconstruction.

1. Shashar, N., Hagan, R., Boal, J.G. \& Hanlon, R.T. Cuttlefish use polarization sensitivity in predation on silvery fish. Vision Res. 40, 71-75 (2000).

2. Cartron, L. et al. Polarization vision can improve object detection in turbid waters by cuttlefish. J. Exp. Mar. Biol. Ecol. 447, 80-85 (2013).

3. Zylinski, S., Darmaillacq, A. \& Shashar, N. Visual interpolation for contour completion by the European cuttlefish (Sepia officinalis) and its use in dynamic camouflage. Proc. R. Soc. B 279, 2386-2390 (2012).

4. Barbosa, A., Allen, J.J., Mäthger, L.M. \& Hanlon, R.T. Cuttlefish use visual cues to determine arm postures for camouflage. Proc. R. Soc. B doi: 10.1098/ rspb.2011.0196 (published online 11 May 2011).

5. Allen, J.J., Bell, G.R.R., Kuzirian, A.M. \& Hanlon, R.T. Cuttlefish skin papilla morphology suggests a muscular hydrostatic function for rapid changeability. J. Morphol. 274, 645-656 (2013).

6. Mäthger, L.M. et al. Bright white scattering from protein spheres in color changing, flexible cuttlefish skin. Adv. Funct. Mater. 23, 3980-3989 (2013).

7. Yu, C. et al. Adaptive optoelectronic camouflage systems with designs inspired by cephalopod skins. Proc. Natl. Acad. Sci. USA 111, 12998-13003 (2014).

8. Velankar, S. Buckling of bilayer laminates-A novel approach to synthetic papillae. Final report. Air Force Research Laboratory Report No. AFRL-OSR-VATR-2013-0530, Contract No. FA9550-10-1-0329. (Air Force Office of Scientific Research, Arlington, VA, 2013).

9. Milovaca, D., Ferrer, G.G., Ivankovic, M. \& Ivankovic, H. PCL-coated hydroxyapatite scaffold derived from cuttlefish bone: Morphology, mechanical properties and bioactivity. Mater. Sci. Eng. C Mater. Biol. Appl. 34, 437-445 (2013).

10. Sarin, P., Lee, S., Apostolov, Z.D. \& Kriven, W M. Porous biphasic calcium phosphate scaffolds from cuttlefish bone. J. Am. Ceram. Soc. 94, 2362-2370 (2011).

11. Li, X. et al. Biotemplated syntheses of macroporous materials for bone tissue engineering scaffolds and experiments in vitro and vivo. ACS Appl. Mater. Interfaces 5, 5557-5562 (2013). 